\title{
CONFERENCIA
}

\section{LACTANCIA MATERNA Y SU CONTRIBUCIÓN AL ADECUADO DESARROLLO DEL SISTEMA ESTOMATOGNÁTICO Y SUS FUNCIONES}

María Paz Moya ${ }^{2}$

La lactancia materna además de los beneficios, tanto para la madre cómo para el hijo, desde el punto de vista inmunológico, nutricional y emocional ampliamente divulgados en la literatura, tiene alta implicancia para la fonoaudiología, dado que se encuentra íntimamente relacionada con el crecimiento y desarrollo del sistema estomatognático.

El feto presenta el reflejo de succión a partir de la trigésima semana de gestación, momento en el cual se encuentra preparado neurológicamente para amamantarse. Por lo anterior, la es considerada la primera función del sistema estomatognático.

La lactancia materna permite el ejercicio necesario para el desarrollo del sistema estomatognático: una serie de músculos masticatorios inician su maduración y posicionamiento (entre ellos, el músculo temporal, pterigoideo lateral y milohioídeo). Además, la lengua estimula el paladar, evitando alguna alteración que pueda ser ejercida por los músculos buccinadores y el músculo orbicular de los labios orienta tanto el crecimiento como el desarrollo de la región anterior del sistema estomatognático.

La lactancia materna también implica una serie de movimientos mandibulares. En conjunto con el movimiento mandibular acontece el desarrollo óseo, de tal forma que, la retrognatia mandibular fisiológica que los bebés presentan al nacer se corregirá de forma natural hasta la época de la erupción de los dientes temporales, para que su oclusión sea adecuada. Por lo tanto, la lactancia materna se torna en sí misma un estímulo para todas las estructuras orales, como labios, lengua, mejillas, huesos y músculos faciales que participan en el proceso.

Lo anteriormente expuesto, hace suponer que la lactancia materna es importante para fortalecer el desarrollo de las demás funciones del sistema estomatognático: masticación, deglución, respiración y fonoarticulación. Pese a lo anterior, es reducido el conocimiento en relación con los efectos de la lactancia materna sobre el desarrollo del sistema estomatognático y su correlación con la presencia de alteraciones de la motricidad orofacial en población pediátrica, de esto da cuenta la escasa cantidad de estudios publicados en los últimos años.

No obstante, Benitez, L. \& Cols., (2009) realizan una revisión de la literatura en Venezuela titulada "Estudio de la lactancia materna como un factor determinante para prevenir las anomalías dentomaxilofaciales", en la cual se plantean los efectos de la lactancia materna sobre el desarrollo de las diferentes estructuras que conforman el aparato bucal, y específicamente su efecto sobre las alteraciones dentofaciales. Dichos autores concluyen que la alimentación al seno materno favorece el crecimiento y desarrollo del aparato masticatorio, evita la adquisición de hábitos deformantes bucales, mejora la oclusión dental en etapas posteriores del desarrollo infantil, previene las anomalías dentomaxilofaciales y contribuye a la prevención de las caries dentales.

2. Fonoaudióloga y Licenciada en Fonoaudiología por la Universidad de Talca - Chile; Magister en Docencia Universitaria por la Universidad Autónoma de Chile. Actualmente se desempeña como Docente de la carrera de Fonoaudiología en la Universidad Autónoma de Chile. 
Asimismo, estudios realizados por Blanco y Cols. (1999) en una población de preescolares arrojó datos significativos. Se encontró un alto porcentaje de niños amamantados con perfil recto $(56,8 \%)$, en contraste con aquellos que no recibieron lactancia materna (38,46\%). Ocurrió además que al incrementarse los meses de lactancia materna, se produce un aumento considerable en el porcentaje de niños con perfil recto, $38,47 \%$, en niños con lactancia artificial, $47,56 \%$ en niños con duración de la lactancia entre 1 y 6 meses, en contraste con 85,19\% en niños con más de 6 meses de lactancia natural. Otro hallazgo encontrado en más de la mitad de la población estudiada se observó paladar profundo $(52,46 \%)$ el cual estaba asociado significativamente con un período de amamantamiento menor a seis meses.

Donato y Cols. (2002) realizaron un estudio llevado a cabo en Costa Rica, donde se evaluaron 225 niños, con la finalidad de determinar los efectos de la lactancia materna sobre el desarrollo normal del maxilar inferior. Se obtuvo como resultado de la investigación, entre otros hallazgos, que un niño promedio que no recibió leche de su madre por más de 3 días después del parto, tiene 2,46 veces más riesgo de tener una relación esquelética clase II que otro que sí recibió.

En 2014, De Gregorio , Espinoza, Troncoso, Vergara y Moya, realizaron un estudio en el sur de Chile, que buscó establecer la relación entre el período de lactancia materna exclusiva y la presencia de alteraciones de la motricidad orofacial en niños pre-escolares. Dicho estudio concluyó que existe una correlación positiva entre ambas variables, es decir, a mayor tiempo de lactancia materna exclusiva, disminuyen las posibilidades de que el menor desarrolle alteraciones de la motricidad orofacial. Específicamente, se identificó la presencia de deglución atípica en menores que recibieron lactancia materna exclusiva por un período inferior a tres meses, presentando interposición lingual, contracción del músculo mentoniano y orbicular de los labios al deglutir. Asimismo, se identificó diagnóstico de respiración oral en menores que se amamantaron naturalmente por un período inferior a 6 meses.

Cabe señalar que la Organización Mundial de la Salud (2014) ha sugerido que la lactancia materna exclusiva ocurra por lo menos durante los seis primeros meses de vida, acompañándose posteriormente con alimentos complementarios hasta los dos años de edad.

Innumerables estudios han demostrado que la alimentación por medio de la lactancia materna desde el nacimiento y por un tiempo mayor a 6 meses contribuye notablemente a la prevención de alteraciones dento - buco - máxilo - faciales y también de carácter fonoaudiológico, tales como deglución atípica, respiración oral y trastornos de habla. Lo anterior, pone de manifiesto la necesidad de considerar este aspecto como un elemento importante para la prevención de alteraciones del sistema estomatognático y funciones de la motricidad orofacial, por parte de los profesionales de la salud en conjunto.

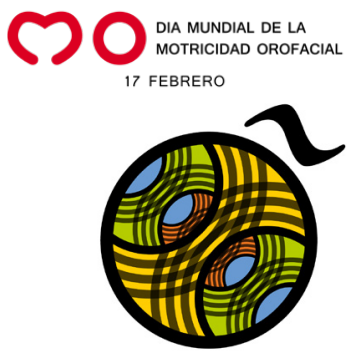

